\title{
Coexistence of urticaria pigmentosa and thalassemia minor in a young adult
}

\author{
Funda Tamer ${ }^{1}$, Haldun Umudum²
}

\begin{abstract}
1 Department of Dermatology, Ufuk University School of Medicine, Ankara, Turkey
\end{abstract}
2 Department of Pathology, Ufuk University School of Medicine, Ankara, Turkey

Key words: urticaria pigmentosa, thalassemia, mastocytosis, young adult

Citation: Tamer F, Umudum H. Coexistence of urticaria pigmentosa and thalassemia minor in a young adult. Dermatol Pract Concept. 2018;8(2):78-79. DOI: https://doi.org/10.5826/dpc.0802a03

Received: September 26, 2017; Accepted: November 22, 2017; Published: April 30, 2018

Copyright: @2018 Tamer et al. This is an open-access article distributed under the terms of the Creative Commons Attribution License, which permits unrestricted use, distribution, and reproduction in any medium, provided the original author and source are credited.

Funding: None.

Competing interests: The authors have no conflicts of interest to disclose.

All authors have contributed significantly to this publication.

Corresponding author: Funda Tamer, MD, Assistant Professor, Department of Dermatology, Ufuk University School of Medicine, Mevlana Bulvari (Konya Yolu), No 86-88, 06510, Balgat, Ankara, Turkey Tel.+903122044151. Email: fundatmr@yahoo.com

An 18-year-old Caucasian patient presented with an asymptomatic skin eruption on his trunk. The patient stated the lesions have been present for 15 years and that the lesions were more prominent and more extensive in childhood. However, the size and number of lesions decreased with time. The past medical history was remarkable for beta thalassemia minor. He had not received any treatment for the skin lesions or thalassemia previously.

Dermatologic examination revealed erythematous, hyperpigmented papules and plaques on the neck, chest and upper back (Figure 1). Darier sign was present. A skin biopsy was performed to reach a definitive diagnosis. Histopathologic evaluation revealed a massive mast cell infiltration and eosinophils in the dermis (Figure 2). The diagnosis of urticaria pigmentosa was made based on clinical and histopathologic features. Laboratory tests, including complete blood count, chemistry panel, complete urinalysis, thyroid-stimulating hormone (TSH), serum iron, ironbinding capacity, ferritin, folate, vitamin $\mathrm{B}_{12}$, sedimentation, C-reactive protein (CRP) and abdominal ultrasonography were performed to rule out systemic involvement. The chemistry panel, urine test, TSH, serum iron, iron-binding capacity, ferritin, folate, vitamin $\mathrm{B}_{12}$, sedimentation, CRP and abdominal ultrasonography were all within normal limits. The complete blood count was normal except for slightly decreased mean platelet volume $(5.98 \mathrm{fL}$, range: 6.4 $-11 \mathrm{fL})$ and slightly elevated eosinophil percentage $(7.8 \%$, range: $0 \%-7 \%$ ). Unfortunately, further diagnostic tests such as serum tryptase level, tryptase in bone marrow blood, histamine and metabolites in a 24-hour urine analysis were not performed. The patient refused bone marrow biopsy due to fear of pain. Therefore, the patient was informed about the triggers of mast cell activation and it was recommended to him that he make regular follow-up appointments.

Urticaria pigmentosa is a form of cutaneous mastocytosis that is characterized by excessive mast cell infiltration of the superficial dermis [1]. It presents with hyperpigmented macules, papules or nodules on the trunk and extremities [2]. Thalassemia minor is a common genetic disorder that is characterized by a mutation in one chain of $\beta$-globin for hemoglobin. The patients with thalassemia minor are usually asymptomatic. Blood tests may reveal mild anemia or normal hemoglobin levels [3]. Urticaria pigmentosa may progress to systemic mastocytosis in $4.5 \%-10 \%$ of cases [1]. Systemic involvement is more common in adults than in children [1]. In these patients, increased histamine levels due to mast 


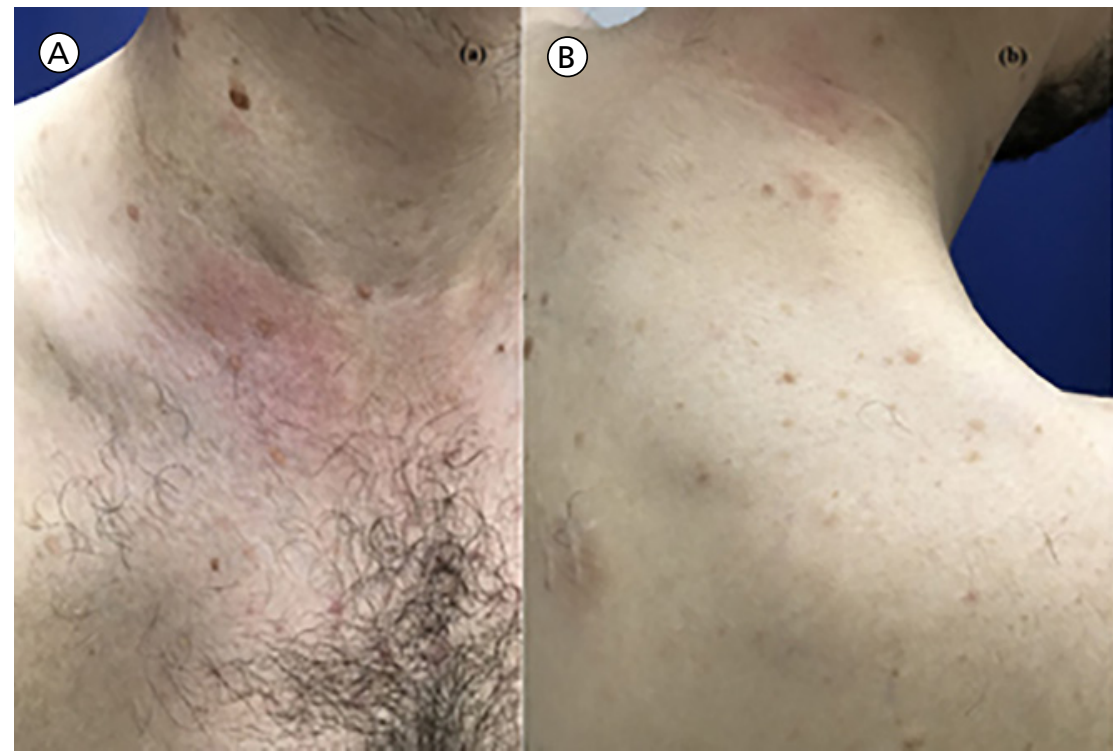

Figure 1. (a) Hyperpigmented papules on the neck and chest. Urticarial plaque indicates a positive Darier's sign. (b) Hyperpigmented macules and papules on the upper back. [Copyright: @2018 Tamer et al.]

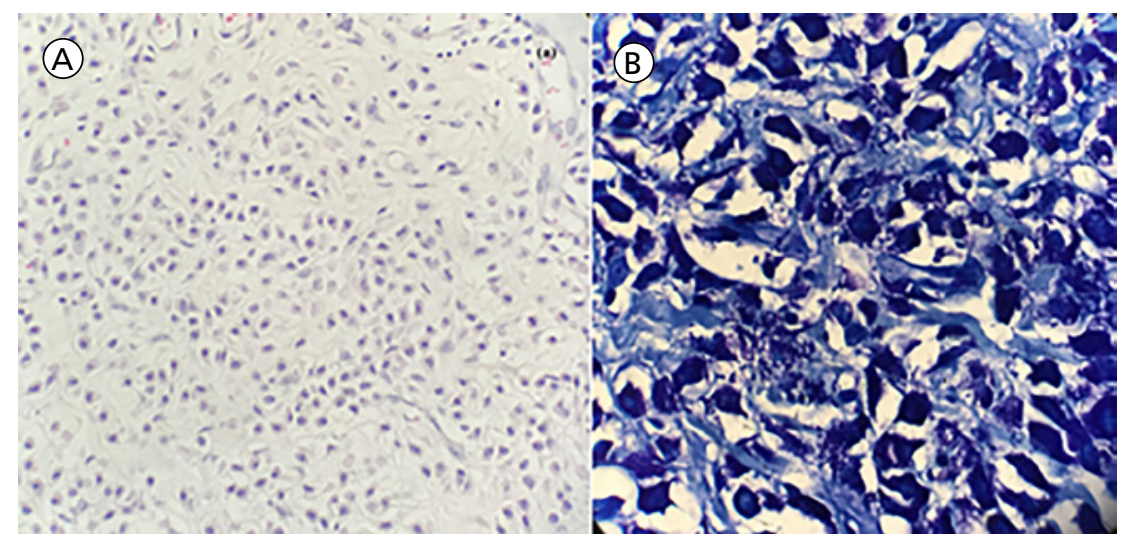

Figure 2. (a) Dense mast cell infiltration with some eosinophils in the dermis (H\&E x40). (b) Numerous mast cells in the dermis (metachromatic staining with toluidine blue x100). [Copyright: (O2018 Tamer et al.]

cell proliferation can lead to diarrhea, bronchospasm, arthralgia, weight loss, and flushing [2].

Elevated serum tryptase level, peripheral blood eosinophilia, skin biopsy, biopsy of the suspected involved organ such as colon or liver, KIT D816V mutation, $\mathrm{CD} 2$ and $\mathrm{CD} 25$ expression of the bone marrow or affected tissue may be helpful in the diagnosis of systemic mastocytosis in adults [4]. Furthermore, Proelss et al suggest that elevated levels of tryptase in the bone marrow may be that coexist with urticaria pigmentosa are polycythemia vera [6], acute lymphoblastic leukemia [7], and massive peripheral eosinophilia [8]. Hodgkin's disease, lymphocytic lymphoma and chronic lymphocytic leukemia have also been associated with urticaria pigmentosa [2].

The case we described is unique in that the patient had both urticaria pigmentosa and thalassemia minor simultaneously. Thalassemia may be considered as a hematologic disorder that can occur in patients with urticaria pigmentosa. However, further studies are required to explain possible common etiological mechanisms.

\section{References}

1. Jappe U, Aumann V, Mittler U, Gollnick H. Familial urticaria pigmentosa associated with thrombocytosis as the initial symptom of systemic mastocytosis and Down's syndrome. J Eur Acad Dermatol Venereol. 2003;17(6):718-722.

2. Ogg GS, Rosbotham JL, MacDonald DM. Urticaria pigmentosa coexisting with multiple myeloma. Clin Exp Dermatol. 1996;21(5):365-366.

3. Choudhry VP. Thalassemia minor and major: current management. Indian J Pediatr. 2017;84(8):607-611.

4. Scherber RM, Borate U. How we diagnose and treat systemic mastocytosis in adults. Br J Haematol. 2017. Epub ahead of print.

5. Proelss J, Wenzel J, Ko Y, Bieber T, Bauer $\mathrm{R}$. Tryptase detection in bone-marrow blood: a new diagnostic tool in systemic mastocytosis. J Am Acad Dermatol. 2007;56(3):453-457.

6. Guevara BEK, Guillano VP, Dayrit JF. Urticaria pigmentosa with concomitant polycythaemia vera in a 3-year-old boy. Clin Exp Dermatol. 2017;42(6):696-698.

7. Lewis HM, Winter E, Darbyshire P, Yoong A, Marsden JR, Moss C. Urticaria pigmentosa and acute lymphoblastic leukaemia. $J$ R Soc Med. 1995;88(9):530-531.

8. Stern RL, Manders SM, Buttress SH, Heymann WR. Urticaria pigmentosa presenting with massive peripheral eosinophilia. Pediatr Dermatol. 1997;14(4):284-286. 